\title{
REVIEW
}

Open Access

\section{Multi-detector computed tomography in the assessment of tetralogy of Fallot patients: is it a must?}

\author{
Mahmoud Shaaban ${ }^{1,2^{*}}$, Sara Tantawy ${ }^{1,3}$, Fatma Elkafrawy ${ }^{1,4}$, Dina Haroun ${ }^{1,5}$, Soha Romeih ${ }^{1,2}$ and Wesam Elmozy ${ }^{1,5}$
}

\begin{abstract}
Background: Tetralogy of Fallot (TOF) accounts for 10\% of all CHD. It classically consists of ventricular septal defect (VSD), aortic overriding, right ventricular outflow tract (RVOT) obstruction, and RV hypertrophy. There are many anatomic variants, associated intracardiac and extracardiac anomalies that must be taken into consideration when imaging and planning the surgical procedure needed. Multi-detector computed tomography (MDCT), with its high spatial and temporal resolution, has a pivotal role in the evaluation of complex anatomical findings in both unrepaired and repaired TOF patients.
\end{abstract}

Main body: Though MDCT has a limited role in the initial diagnosis of TOF, it is particularly important when there is a question about anatomy of pulmonary arteries (PAs) (whether sizable, hypoplastic, or atretic), presence of major aorto-pulmonary collaterals (MAPCAs) and presence of additional VSDs. Additionally, MDCT is crucial in the diagnosis of different anatomical variants of TOF. TOF patients with absent pulmonary valve classically have hugely dilated PAs which raise an important question about the degree and severity of airways compression. This question can be accurately answered by MDCT. TOF with double-outlet RV (DORV) has variable degrees of aortic override which can be assessed by MDCT. An atrio-ventricular septal defect (AVSD) is seen in about 13\% of TOF cases and typically occurs in patients with Down syndrome. MDCT can assess the size and extent of inlet VSD and size of both ventricles (balanced or unbalanced AVSD). Coronary artery anomalies are common and important association. MDCT can identify the presence of a major coronary artery crossing the RVOT, a left anterior descending (LAD) from RCA, or a dual LAD. The clinical importance of these anomalies is its susceptibility to injury during ventriculotomy incision required for TOF repair necessitating changing the usual approach of surgery.

Patients with reduced pulmonary blood flow undergo a systemic to pulmonary shunt. MDCT can assess the patency of the shunt, stenotic, or occluded segments. In surgically repaired TOF patients, MDCT can identify the sequalae and long-term complications including residual RVOT obstruction, conduit stenosis, RVOT patch aneurysm, $\mathrm{RVH}$, and aortic root dilatation.

Conclusion: MDCT is a safe and reliable imaging modality that provides accurate assessment of anatomical variants and associated anomalies of TOF.

Keywords: Multi-detector computed tomography, Tetralogy of Fallot, Congenital heart disease, MAPCAs, DORV, AVSD, Coronary anomalies, Systemic-to-pulmonary shunts

\footnotetext{
* Correspondence: mahmoud.shaban@med.tanta.edu.eg

${ }^{1}$ Aswan Heart Centre (Magdi Yacoub Foundation), Aswan, Egypt

${ }^{2}$ Cardiology department, Faculty of medicine, Tanta University, Tanta, Egypt

Full list of author information is available at the end of the article
}

\section{Springer Open}

(c) The Author(s). 2020 Open Access This article is licensed under a Creative Commons Attribution 4.0 International License, which permits use, sharing, adaptation, distribution and reproduction in any medium or format, as long as you give appropriate credit to the original author(s) and the source, provide a link to the Creative Commons licence, and indicate if changes were made. The images or other third party material in this article are included in the article's Creative Commons licence, unless indicated otherwise in a credit line to the material. If material is not included in the article's Creative Commons licence and your intended use is not permitted by statutory regulation or exceeds the permitted use, you will need to obtain permission directly from the copyright holder. To view a copy of this licence, visit http://creativecommons.org/licenses/by/4.0/. 


\section{Background}

Tetralogy of Fallot (TOF) is the most common cyanotic congenital heart disease (CHD). In neglected untreated cases, the mortality rate is about 33\% in the first year of life and about $50 \%$ in the first 3 years of life [1]. However, advances in diagnosis, surgical techniques, and postoperative treatment have led to increasing number of patients reaching adulthood with a dramatic increase in survival rate to almost $90 \%$ at 30 years. TOF was originally named after the French scientist "Arthur Louis Etienne Fallot" who published a paper in 1988 entitled "Contribution a 'l'anatomie pathologique de la maladie bleue" [2]. He described four anatomical features that were almost always present in all post-mortem specimens of the blue patients "la maladie bleue" in his own words. These anatomical features consist of a tetrad of (1) ventricular septal defect (VSD), (2) aortic overriding, (3) right ventricular outflow tract (RVOT) obstruction, and (4) right ventricular (RV) hypertrophy [3].

\section{Pathophysiology}

The main pathophysiological features of TOF are the antero-cephalic deviation of the cono-ventricular septum and hypertrophy of the septoparietal trabeculations of the RVOT [3]. The antero-cephalic deviation of the cono-ventricular septum results in a mal-aligned VSD in continuity of the aortic valve [4]. Thus, the aortic valve has a biventricular connection with variable degrees of overriding the RV. In addition, the mal-alignment between the cono-ventricular septum and the septoparietal trabeculations of the RVOT results in hypertrophy of the RVOT and subsequent pulmonary valvular or infundibular stenosis [5-8]. The hemodynamic effect of RVOT obstruction is right ventricular hypertrophy which is the fourth pathological feature of TOF [3].

\section{Clinical presentation and diagnosis}

Although TOF is the most common cyanotic congenital heart disease, only a small percentage of cases are deeply cyanotic since birth after closure of the ductus arteriosus. This group of cyanotic patients is referred to as "blue TETs" while the acyanotic group is referred to as "pink TETs". Blue TETs typically have severe pulmonary stenosis or atresia. Sometimes, these patients may remain undiagnosed in the first days or weeks of life due to the presence of moderate to large patent ductus arteriosus (PDA) which maintains adequate blood flow to lungs and present with profound cyanosis after duct closure necessitating emergency surgery to maintain adequate pulmonary blood flow.

Pink TETs may have mild desaturation with arterial oxygen saturation in the range of $80-90 \%$ or even normal oxygen saturation depending on the degree of pulmonary stenosis and the presence of PDA or major aorto-pulmonary collateral arteries (MAPCAs). Usually, the baseline oxygen saturation gradually decreases as the right ventricular hypertrophy (RVH) progress and subsequently the degree of RVOTO. These patients should be closely followed up to determine the appropriate time of surgical intervention before cyanosis worsens. Pink TETs can develop episodic profound hyper-cyanosis "cyanotic spells" with arterial oxygen saturation drop to below $50 \%$ and manifest by sudden marked increase in cyanosis, shortness of breath, agitation, and loss of consciousness. These cyanotic spells result from dynamic changes in the pulmonary and systemic resistance which is thought to be due to infundibular muscle spasms with large dynamic increase in RVOT obstruction resulting in severe right to left shunting of blood through the VSD [9].

Clinical examination of TOF patients can reveal variable degrees of cyanosis, ranging from mild to severe generalized cyanosis. Clubbing may be seen in neglected cases. On auscultation, an ejection systolic murmur can be heard due to RVOT obstruction which usually soften or disappear during cyanotic spells as a result of marked decrease of blood flow across RVOT. The VSD typically has no appreciable murmur because of its large size and systemic level pressure in the RV. Usually, there is no splitting of second heart sound because of small pulmonary valve and low post-stenotic pulmonary artery pressure [9]. Electrocardiogram shows right ventricular hypertrophy and right axis deviation.

Classical finding in chest radiography is the "bootshaped" heart resulting from RVH and small pulmonary knob and the lung is usually oligemic due to decreased pulmonary blood flow.

Echocardiography is the diagnostic modality of choice. It provides complete evaluation of the anatomy, estimation of pressure gradient across the RVOT, identification of the level of RVOT obstruction, and delineation of coronary artery anatomy [10]. Prenatal echocardiography is highly accurate in the in utero diagnosis of TOF, although the degree of pulmonary stenosis is usually difficult to be determined. More data are needed to identify the effect of prenatal diagnosis on long-term survival [11]. Three-dimensional echocardiography is not yet superior to two-dimensional echocardiography in diagnosis and preoperative assessment of TOF, though it may be of great value in long-term follow-up of functional and morphological changes to the RV in repaired TOF patients [12].

Before the advanced techniques in echocardiography, cardiac catheterization was used to be the gold standard for the diagnosis of TOF. However, in the current days, the use of cardiac catheterization is limited and preserved only for cases with unclear anatomy of branch pulmonary arteries and to confirm the 
presence of anomalous coronary artery. As a good alternative to invasive cardiac catheterization, threedimensional computed tomography and magnetic resonance imaging play an important role in the evaluation of TOF anatomy. These modalities can accurately reveal branch pulmonary arteries, aortic arch anatomy, and also delineate coronary anomalies.

Cardiac magnetic resonance (CMR) is currently considered as one of the most used modalities for long-term evaluation of repaired TOF patient. CMR measurements of RV volumes and function and accurate quantification of pulmonary valve regurgitation volume and fraction, in addition to monitoring the progress of pulmonary regurgitation and RV dilatation, are superior to those obtained by two-dimensional and three-dimensional echocardiography $[13,14]$. These CMR measurements are becoming very dependable indications for timing of re-interventions and most importantly the timing of pulmonary valve replacement [15].

In addition to standard CMR protocols, timeresolved 3D phase contrast MRI (also called 4D flow MRI) improves the visualization and quantification of blood flow in the cardiovascular system that helps in obtaining more detailed information about vascular hemodynamics. Thus, this technique may be a promising method to accurately evaluate altered blood flow in patients with CHD with complex anatomy and hemodynamics.

\section{Medical management}

There is no definitive medical management of TOF patients, and the only definitive management is surgical repair. However, there are few significant medical adjuncts, the most important of which is the Prostaglandin E1 (PGE1) which is used in profoundly cyanosed neonates to maintain the patency of ductus arteriosus [16]. PGE1 is given as a continuous intravenous infusion at a dose of $0.01-0.1 \mu \mathrm{g} / \mathrm{kg} / \mathrm{min}$, to maintain ductal patency, thus providing maintained pulmonary blood flow until definitive surgical correction or palliative surgery by establishment of systemic to pulmonary shunt. Administration of PGE1 is mainly limited to the first week of life, after which PGE1 rarely results in duct opening. The most important and significant side effect of PGE1 is apnea which may require endotracheal intubation and mechanical ventilation.

Other medical adjuncts are mainly aiming to prevention or treatment of cyanotic spells. Beta-blockers may be used in prevention of these spells by reducing the muscular spasm in the RVOT infundibulum [17, 18]. However, it has been shown that TOF patients receiving beta-blockers are at increased risk of inotropes dependence and temporary pacing following surgical repair [19]. Thus, earlier surgical management is recommended in patients with paroxysmal spells requiring betablockers.

Acute management of cyanotic spells includes placing the patient in knee head position, proper oxygenation, sedation, volume resuscitation, and alphareceptor antagonists like phenylephrine which cause systemic vasoconstriction, increase systemic vascular resistance, decrease right to left shunting of the blood across the VSD, and thus increase the pulmonary blood flow [20]. However, any TOF patient requiring such therapy should be referred for urgent surgical management.

\section{Surgical options}

Before the introduction of surgical interventions for TOF, the mortality was about $35 \%$ of patients at the first year of life, $50 \%$ at the age of 3 years and the survival after the age of 30 years was rare [21]. Nowadays, almost all patients that undergo surgical correction are expected to reach adult life.

The best timing for elective surgical repair is now considered to be within the first year of life [22, 23]. Early surgical repair before the age of 3 months has been reported to be associated with extended intensive care stay and hospitalization [22], So such an early repair should be reserved only for patients with severe cyanosis or cyanotic spells. Late surgical correction after the age of 1 year may be associated with complications of long-lasting right ventricle pressure overload and cardiomyopathy due to long-term hypoxemia, which has been related to ventricular dysfunction and arrhythmias [22].

\section{Complete surgical repair}

The aim of the corrective surgery is to completely close the VSD and relieve the RVOT obstruction, with preservation of the right ventricular and pulmonary valve functions. Surgical approach during the early years of corrective surgery was through right ventriculotomy. However, from the mid-sixties, transatrial-transpulmonary approaches with or without patch repair of the outflow tract improved early to middle-term outcome [24]. Currently, surgical correction of TOF may consist of complete relief of RVOT obstruction with extensive resection of infundibular muscles, but often at the expense of pulmonary valve regurgitation, or sometimes accepting residual obstruction in order to preserve pulmonary valve function, aiming to minimizing late surgical sequalae [23].

\section{Palliative procedures}

Palliative procedures are usually performed in patients who are unfit or have contraindications to corrective 
surgery including aberrant coronary arteries, hypoplastic or small caliber pulmonary arteries, and associated cardiac malformations. The aim of palliative surgery is to increase the pulmonary blood flow so as to promote the growth of pulmonary arteries in preparation for corrective surgery at second stage. Various types of palliative procedures have been developed over time. The current palliative surgery procedure of choice is the modified Blalock-Taussig (MBT) shunt, where a Gore-Tex graft is placed between one of the arch vessels and the pulmonary artery. Typically, the shunt is placed on the opposite side of the aortic arch; thus, a patient with a left sided aortic arch receives a right sided MBT shunt. This shunt increases pulmonary blood flow and helps the pulmonary arteries to grow [25].

\section{Multi-detector computed tomography in tetralogy of Fallot}

Non-invasive cardiac imaging plays a critical role in the initial diagnosis and follow-up of TOF patients. Echocardiography is the initial modality of choice for making the diagnosis and follow-up. However, multi-detector computed tomography (MDCT), with its high spatial and temporal resolution, provides detailed depiction of cardiac anatomy and morphology and thus has a pivotal role in the evaluation of complex anatomical findings in both unrepaired and repaired TOF patients. In addition, performing and interpreting cardiac CT examination in unrepaired TOF is essential to guide the surgical intervention needed for repair.
The anatomy of pulmonary arteries

MDCT is particularly important when there is a question about anatomy of pulmonary arteries. The main pulmonary artery and/or one of its right and left branches may be sizable, hypoplastic, or even atretic (Fig. 1). This is critical to identify because patients with hypoplastic or atretic pulmonary arteries will undergo a palliative procedure while patients with sizable pulmonary arteries may be good candidates for corrective surgery.

\section{Major aorto-pulmonary collateral arteries (MAPCAs)}

The majority of these systemic to pulmonary collaterals originate from the descending thoracic aorta; however, they may also originate from the aortic arch, distal thoracic aorta, subclavian, and internal mammary or left coronary arteries (Fig. 2). The modality of choice to identify these MAPCAs is the MDCT and it is critical to identify because these MAPCAs must be closed either percutaneously or surgically during complete corrective surgery in order to avoid pulmonary over flow after surgical correction.

\section{Additional ventricular septal defects (VSD)}

The VSD is a sequel of antero-cephalic deviation of cono-ventricular septum. The most common type is the peri-membranous type which occurs in about $80 \%$ of cases. The VSD is typically large and can be identified easily by echocardiography. However, this cono-ventricular VSD may be accompanied by additional VSDs with an incidence of 5\% [26]. These VSDs are usually small muscular, requiring special

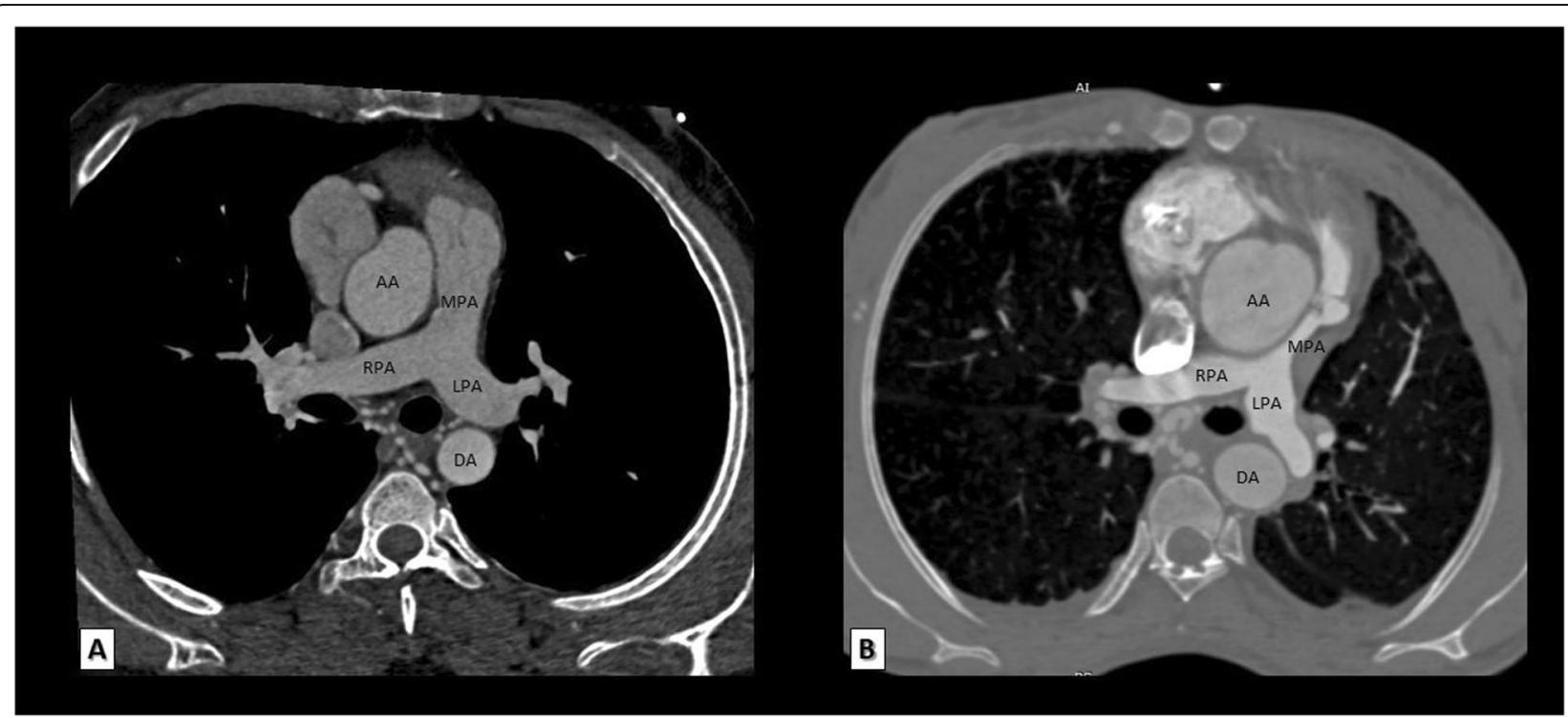

Fig. 1 Reformatted MDCT axial images of two different patients. The first patient with sizable main pulmonary artery as well as its right and left pulmonary branches (a) and the second patient with sizable right and left pulmonary arteries but with hypoplastic main pulmonary artery (b). AA, ascending aorta; MPA, main pulmonary artery; RPA, right pulmonary artery; LPA, left pulmonary artery; DA, descending aorta 


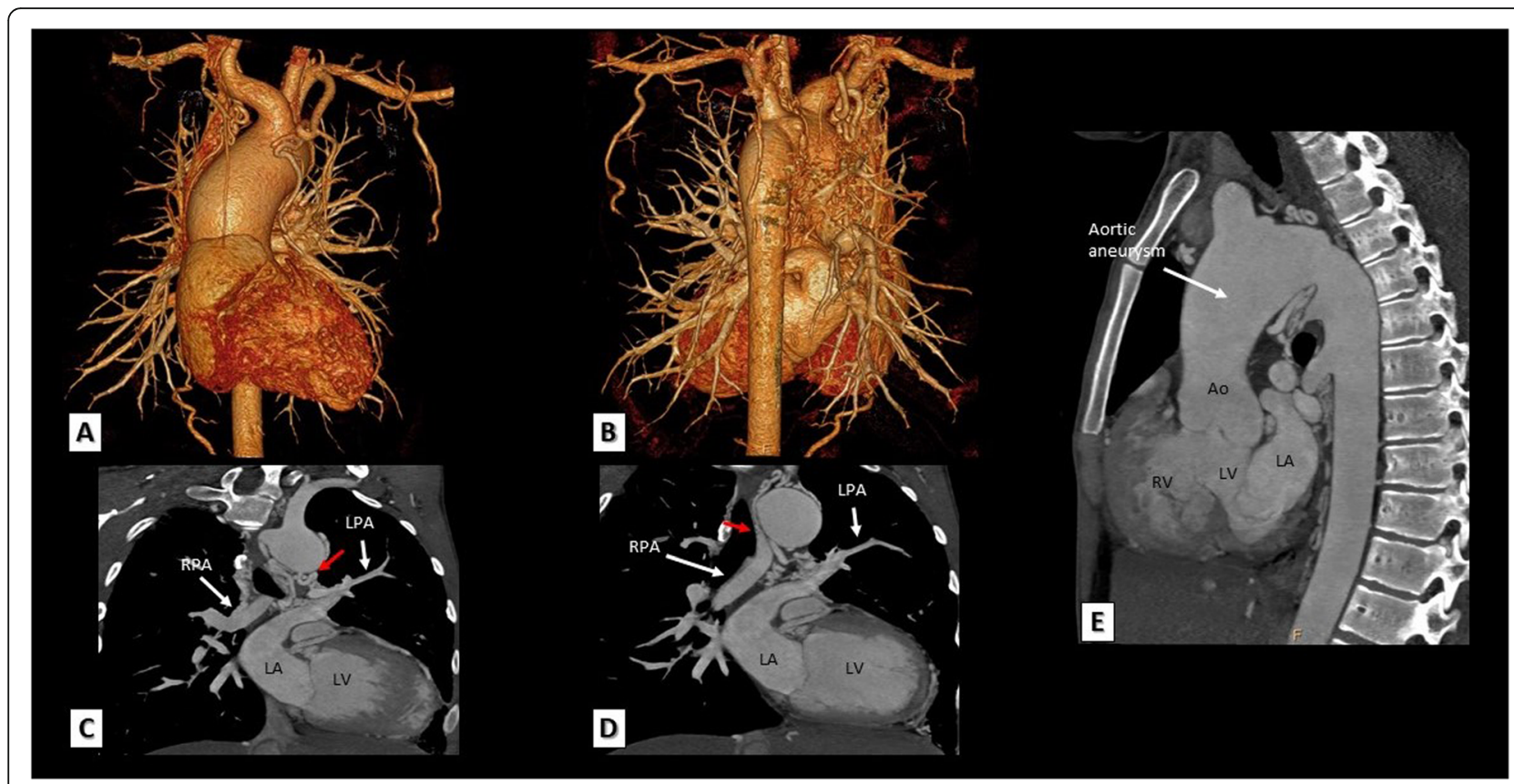

Fig. 2 A neglected adult case with TOF and pulmonary atresia. a, b 3D VRT MDCT images showing innumerous MAPCAs filling the mediastinum arising from descending thoracic aorta as well as right and left subclavian and internal mammary arteries. $\mathbf{c}$, d Reconstructed MDCT coronal images showing pulmonary atresia and non-confluent right and left pulmonary arteries arising from MAPCAs rather than main pulmonary artery (red arrows). e A reconstructed MDCT sagittal image showing ascending aortic aneurysm as a result of long-standing volume loading in this patient. Ao, aorta; RPA, right pulmonary artery; LPA, left pulmonary artery; LV, left ventricle; RV, right ventricle; LA, left atrium.

attention as they may be sometimes difficult to identify by echocardiography because the equalized LV and RV pressures-as a result of the large conoventricular VSD-make no significant pressure gradient across these additional VSDs. Here comes the crucial role of MDCT in identifying these additional VSDs which-if present-must be closed during surgical repair to avoid pulmonary over flow after surgical correction.

\section{MDCT in identification of different anatomic variants of TOF \\ TOF with atrio-ventricular septal defect (AVSD)}

An AVSD is seen in about 13\% of TOF cases [27] and TOF with associated AVSD occurs typically, but not exclusively, in patients with trisomy 21 "Down syndrome" [28]. The rule in such cases is a common AV valve "complete type", but rarely, it may associated with two separate AV valves "Intermediate type" [29]. MDCT can assess the size and extent of inlet VSD and also the size of both ventricles to determine whether this is a balanced or unbalanced AVSD (Fig. 3). This is pivotal in the decision of surgery because TOF patients with balanced AVSD may undergo complete surgical repair while patients with unbalanced AVSD may undergo single ventricle palliation.

\section{TOF with associated coronary anomalies}

An important association with TOF is coronary artery anomalies, the most frequent of which is a major coronary artery passing anteriorly and crossing the RVOT which accounts for approximately $5-12 \%$ of TOF cases. The most frequently and significantly involved major coronary artery is the left anterior descending (LAD) coronary artery originating from the right coronary artery (RCA) and crossing anteriorly the subepicardial surface of the RVOT shortly below the pulmonary annulus to reach the anterior interventricular groove. The clinical importance of this anomalous LAD artery is its susceptibility to injury during ventriculotomy incision required for TOF repair necessitating changing the usual approach of surgery [30]. Less commonly, a dual LAD coronary artery originating from both the RCA and the left main (LM) coronary artery may occur. Rarely, all coronary arteries may originate from a single ostium within the right sinus of Valsalva. Sometimes, one or two accessory coronary ostia can be detected within the right sinus of Valsalva giving origin to one or more conal branching also crossing the RVOT anteriorly [30]. These branches are only considered significant and represent a contraindication to ventriculotomy if their calibers are equal to or larger than the caliber of RCA. MDCT can reliably identify all forms of coronary anomalies and guide the surgical approach for TOF patients (Figs. 4 and 5). 


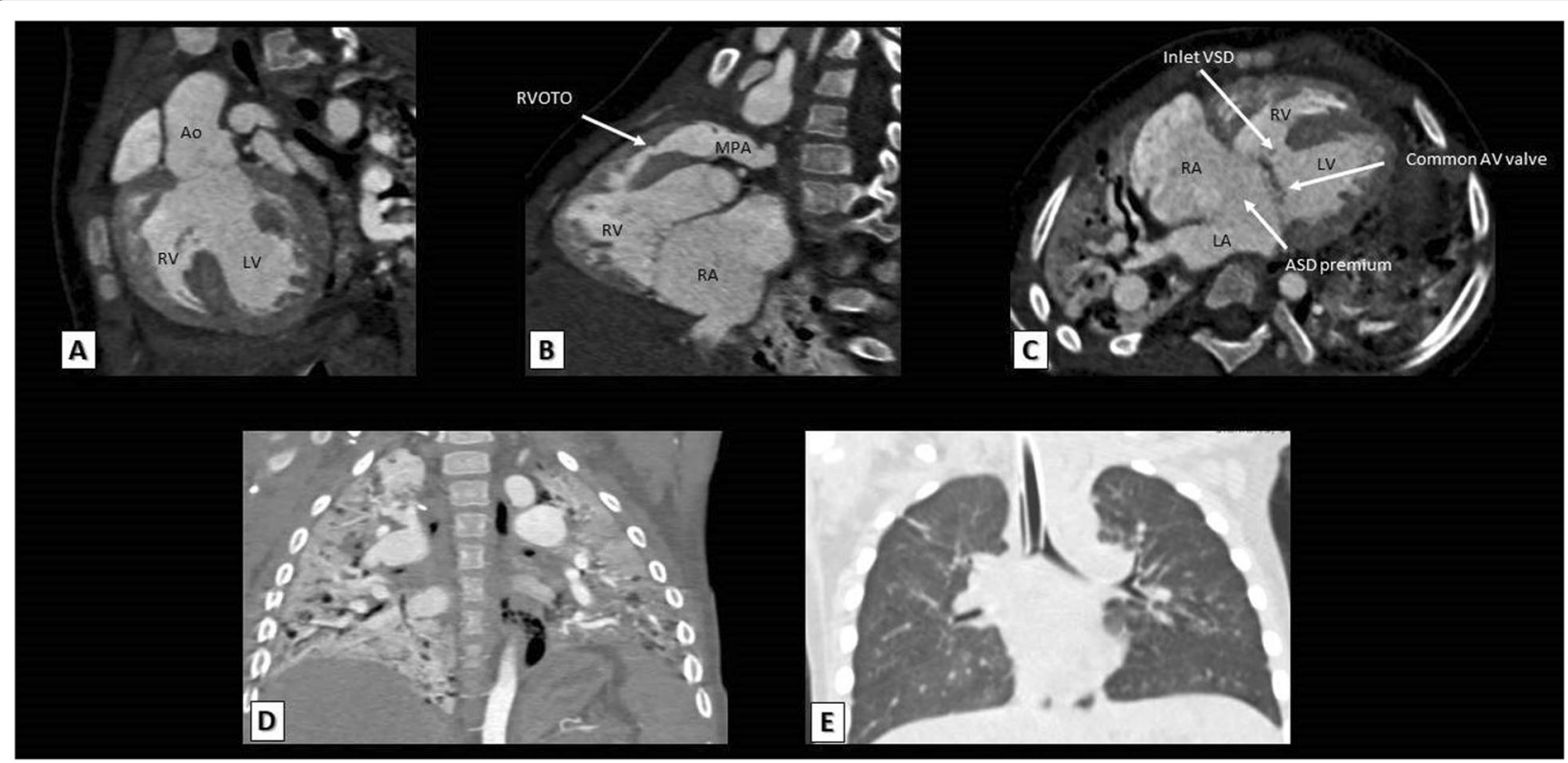

Fig. 3 a, b: Reconstructed MDCT coronal and sagittal images showing overriding of aorta over the VSD (a), RVOT obstruction and RV hypertrophy (b). c A reformatted MDCT axial image showing a complete AVSD with ostium premium ASD, a common AV valve, and an outlet VSD. $\mathbf{d}$ Bilateral transient total lung collapse as a result of airway obstruction during anesthesia, which completely resolved minutes later after airway tube insertion (e). Ao, aorta; LV, left ventricle; RV, right ventricle; LA, left atrium; RA, right atrium; MPA, main pulmonary artery; RVOTO, right ventricular outflow tract obstruction

\section{TOF with atrial septal defect (ASD)}

A patent foramen ovale "PFO" or an ostium secondum ASD is a common association with TOF and is known as pentalogy of Fallot. The size and extent of this defect can be easily and surely identified by MDCT (Fig. 6).

\section{TOF with absent pulmonary valve}

TOF patients with absent pulmonary valve classically have hugely dilated pulmonary arteries which raise an important question about the degree and severity of airways compression. The lower trachea and right and/or left main bronchus can be affected. Prolonged external compression may lead to tracheomalacia or bronchomalacia. The degree of airway compression can be accurately assessed by MDCT (Fig. 7).

\section{TOF with double-outlet right ventricle (DORV)}

TOF is associated with variable degrees of aortic override. The mode of ventriculo-arterial connection may be concordant when more than $50 \%$ of the aorta is supported by the LV or double-outlet ventricular connection may occur when more than $50 \%$ of the aorta is supported by the RV. This is the DORV variant of TOF. The degree of aortic override can be easily detected by MDCT (Fig. 8).

\section{MDCT in TOF patients after palliative procedures}

Palliative systemic to pulmonary shunts are usually performed in patients with small or hypoplastic pulmonary arteries in order to increase the pulmonary blood flow and thus promote the growth of pulmonary arteries. Evaluation of these shunts is an important indication of MDCT which can accurately evaluate shunt patency and any stenotic or occluded segments (Figs. 9, 10, and 11). As an alternative to surgical palliation, some selected patients with favorable anatomy may undergo percutaneous stenting of RVOT, PDA, or branch pulmonary arteries. MDCT is essential for evaluation of endovascular stents and can reliably evaluate the patency and position of these stents (Fig. 12).

\section{MDCT in surgically repaired TOF patients}

\section{Pulmonary regurgitation (PR) and $R V$ dilatation}

$\mathrm{PR}$ is one of the most commonly encountered complications following TOF repair. It is typically well tolerated in the short term due to RV hypertrophy which adapts the volume overload caused by PR. However, long-standing chronic PR can result in RV dilatation and failure, increasing tricuspid valve regurgitation, impaired exercise performance, supraventricular or ventricular arrhythmias, and sudden death [31]. MDCT is excellent in depicting the morphology of the RVOT and cardiac abnormalities related to PR in addition to accurate measurements of enlarged RV volumes which serve as one of the major criteria for PV replacement. 


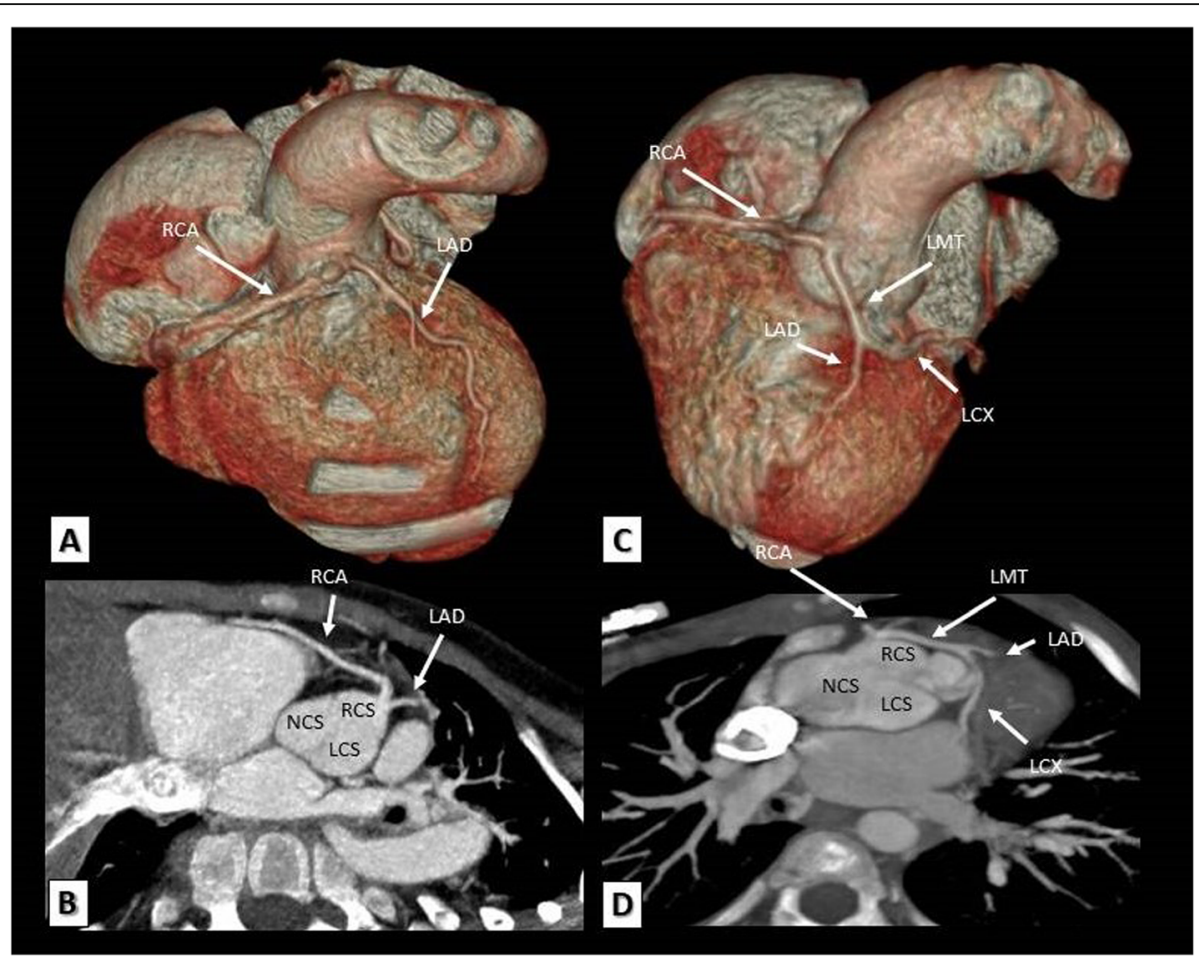

Fig. 4 a, b A TOF patient. a 3D VRT and $\mathbf{b}$ reformatted MDCT axial images showing the left anterior descending artery arising from the right coronary sinus and crossing the RVOT anteriorly to reach the anterior inter-ventricular groove. $\mathbf{c}, \mathbf{d}$ Another TOF patient. $\mathbf{c}$ A VR and $\mathbf{d}$ a reformatted MDCT axial images showing a long left main trunk originating from the right coronary artery and crossing the RVOT anteriorly before it bifurcates to left anterior descending and left circumflex coronary arteries. LAD, left anterior descending; RCA, right coronary artery; LMT, left main trunk; LCX, left circumflex coronary artery; RCS, right coronary sinus; LCS, left coronary sinus; NCS, non-coronary sinus

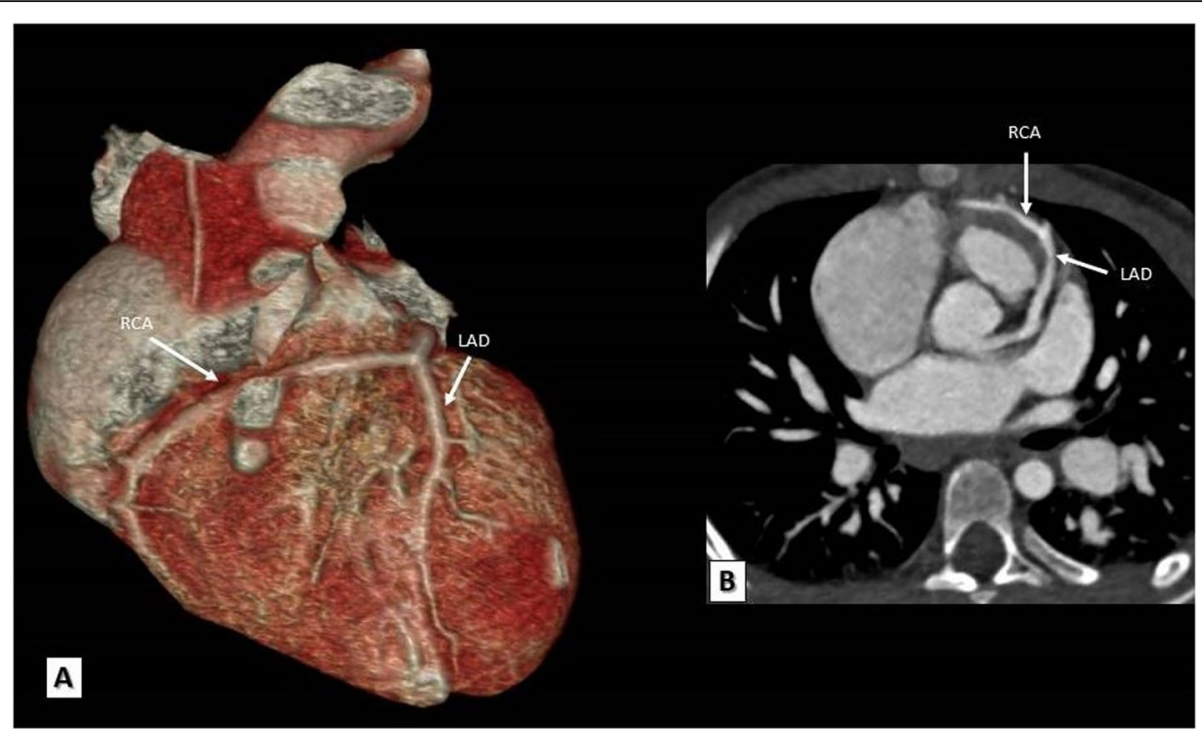

Fig. 5 a, b A TOF patient. a 3D VRT and $\mathbf{b}$ reformatted MDCT axial images showing the right coronary artery arising from the left anterior descending artery and crossing the RVOT anteriorly to reach the right atrio-ventricular groove. LAD, left anterior descending; RCA, right coronary artery 


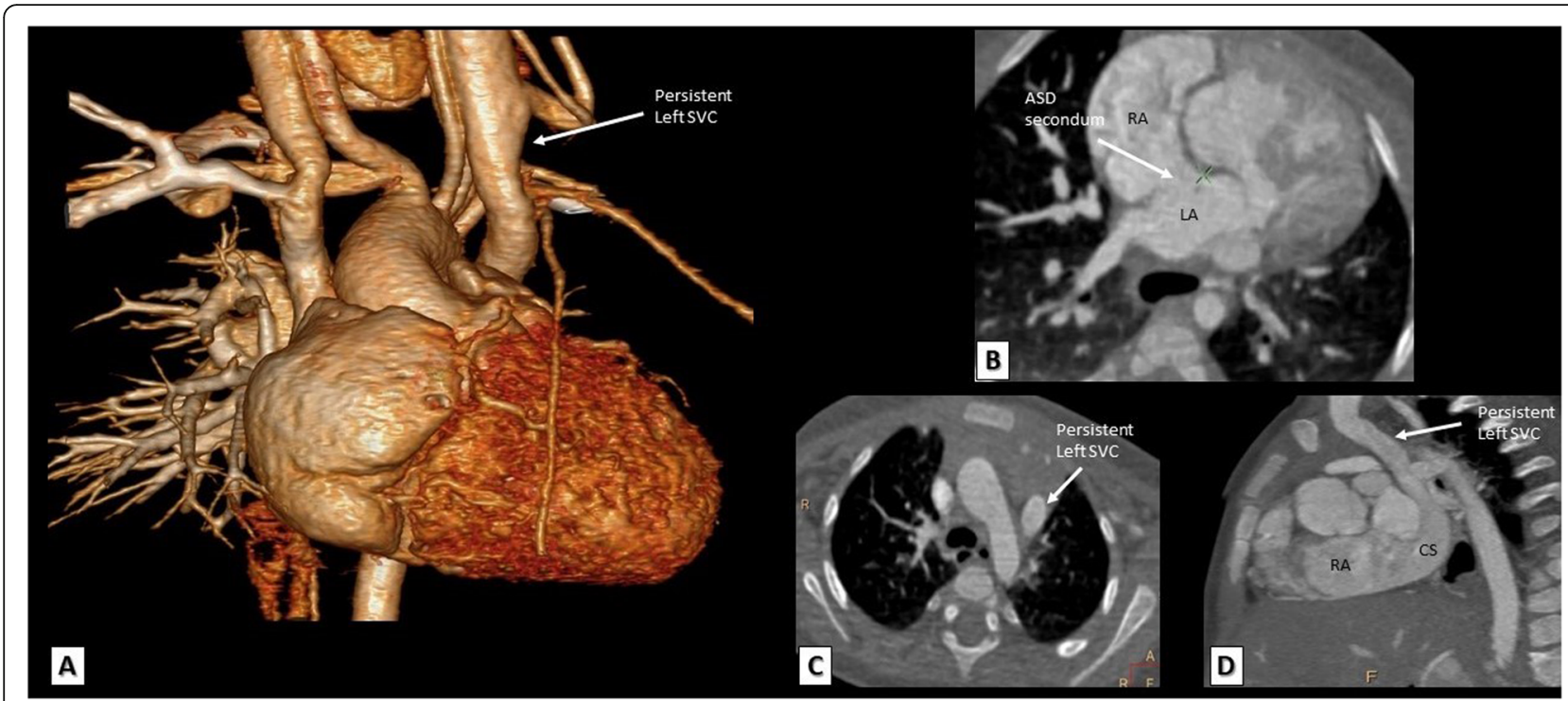

Fig. 6 a A 3D VRT. b, c Reformatted axial and $\mathbf{d}$ reconstructed sagittal MDCT images. This TOF patient has an associated ostium secondum ASD (b) in addition to persistent left superior vena cava draining into the coronary sinus (a, c, d). ASD, atrial septal defect; SVC, superior vena cava; RA, right atrium; CS, coronary sinus; LA, left atrium

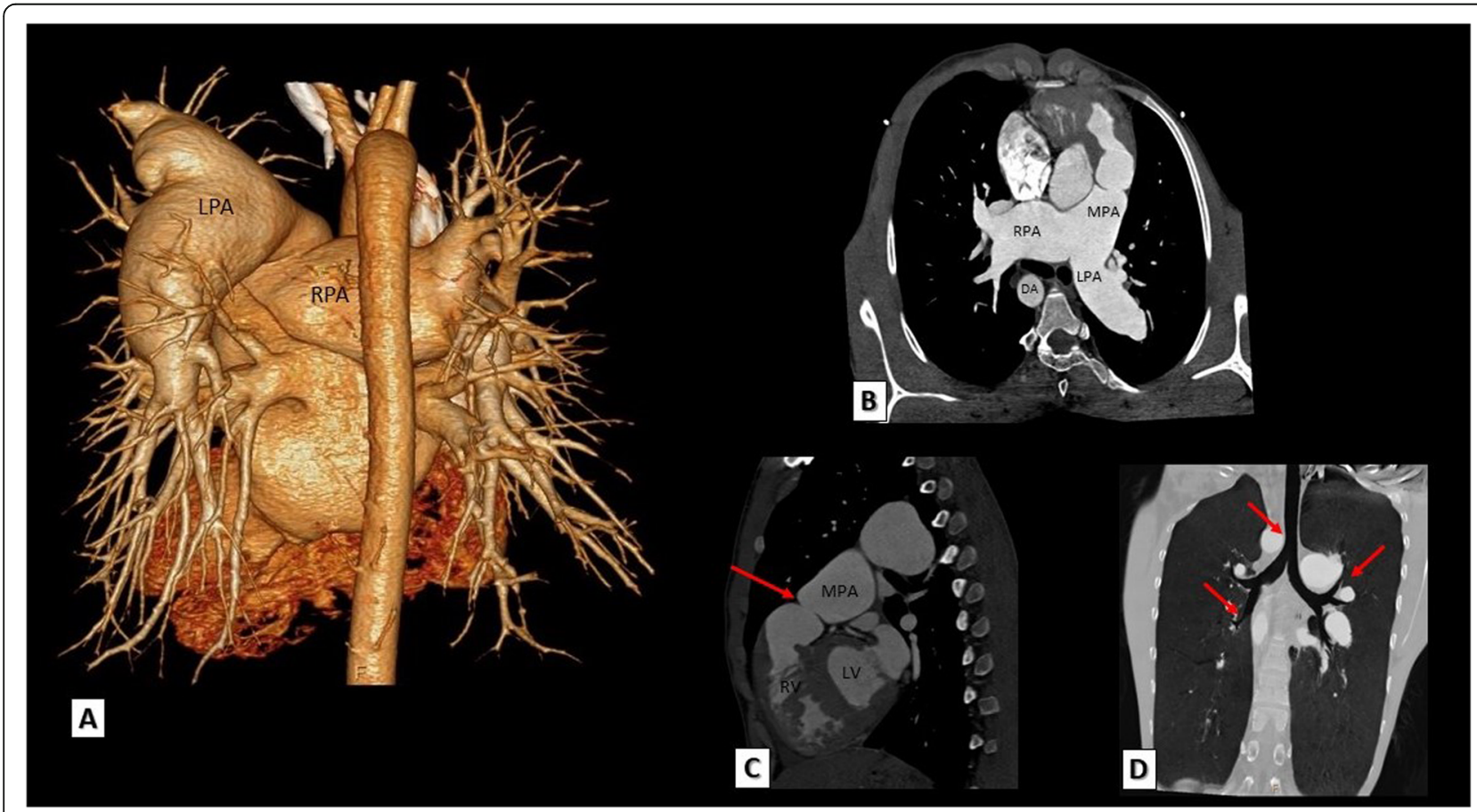

Fig. 7 A case of TOF with absent pulmonary valve. a 3D VRT and $\mathbf{b}$ reformatted axial MDCT images showing hugely dilated pulmonary arteries. Note the associated right sided aortic arch. c A reconstructed sagittal MDCT image showing absent pulmonary valve (red arrow) and RVOT obstruction. d A reconstructed coronal MDCT MIP image showing mild compression on trachea and airway (red arrows). RPA, right pulmonary artery; LPA, left pulmonary artery; MPA, main pulmonary artery; DA, descending aorta; LV, left ventricle; RV, right ventricle 


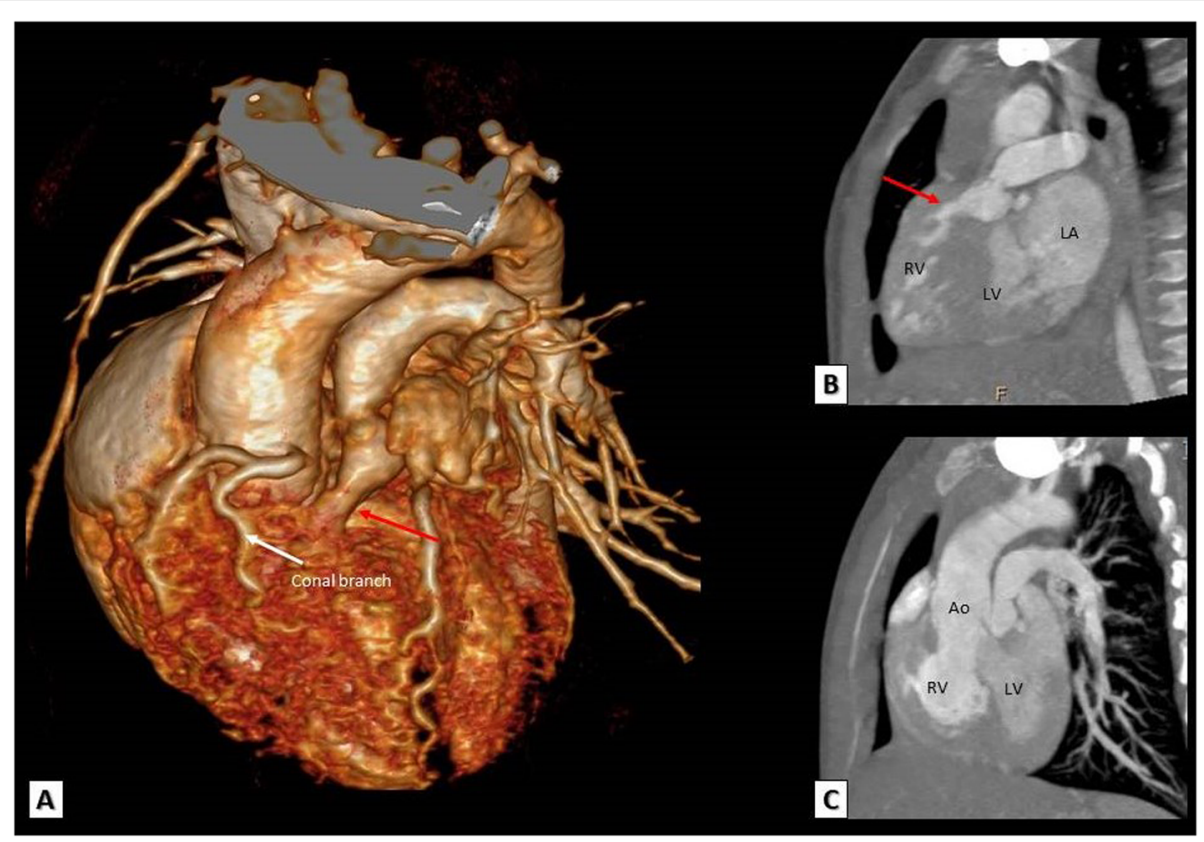

Fig. 8 a A 3D VRT. b Reconstructed coronal and $\mathbf{c}$ reconstructed sagittal MDCT images showing a double-outlet right ventricle where the pulmonary artery and more than $50 \%$ of the aorta originate from the right ventricle. Note the RVOT obstruction (red arrows) and a significant conal branch crossing the RVOT that should be avoided during surgical incision. Ao, Aorta; LV, left ventricle; RV, right ventricle; LA, left atrium

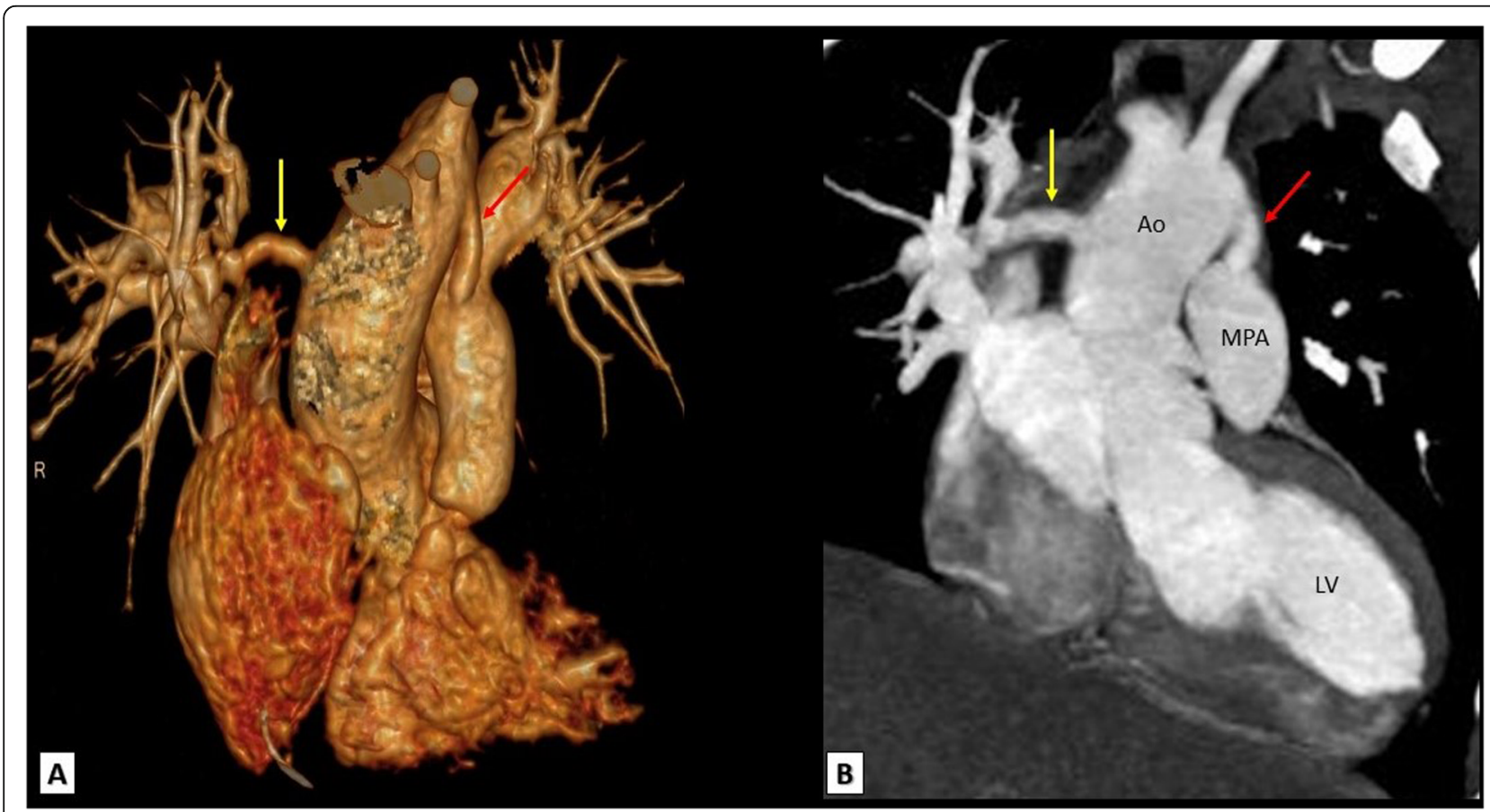

Fig. 9 A TOF patient with bilateral central shunts. a 3D VRT and $\mathbf{b}$ reconstructed coronal MDCT images showing a patent central shunt between the aortic arch and main pulmonary artery (red arrows) and another patent central shunt between the ascending aorta and distal right pulmonary artery (yellow arrows). Ao, Aorta; MPA, main pulmonary artery; LV, left ventricle 


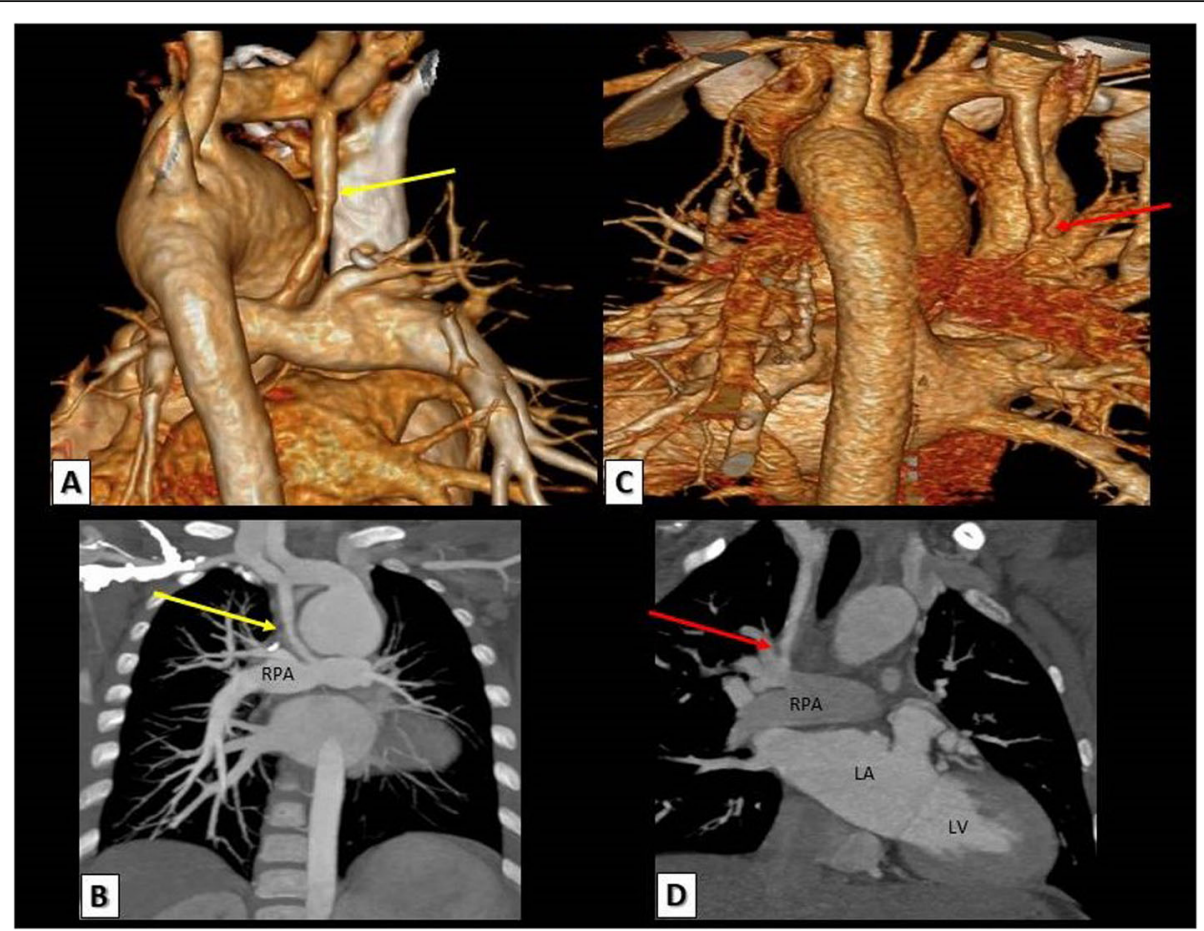

Fig. 10 a, b A TOF patient with right MBT shunt. a 3D VRT and $\mathbf{b}$ reconstructed coronal MDCT images showing a patent MBT shunt between the right subclavian artery and right pulmonary artery. c, d Another TOF patient with also right MBT shunt. c 3D VRT and $\mathbf{d}$ reconstructed coronal MDCT images showing a significant stenosis at the pulmonary end of the MBT shunt. RPA, right pulmonary artery; $L A$, left atrium; $L V$, left ventricle

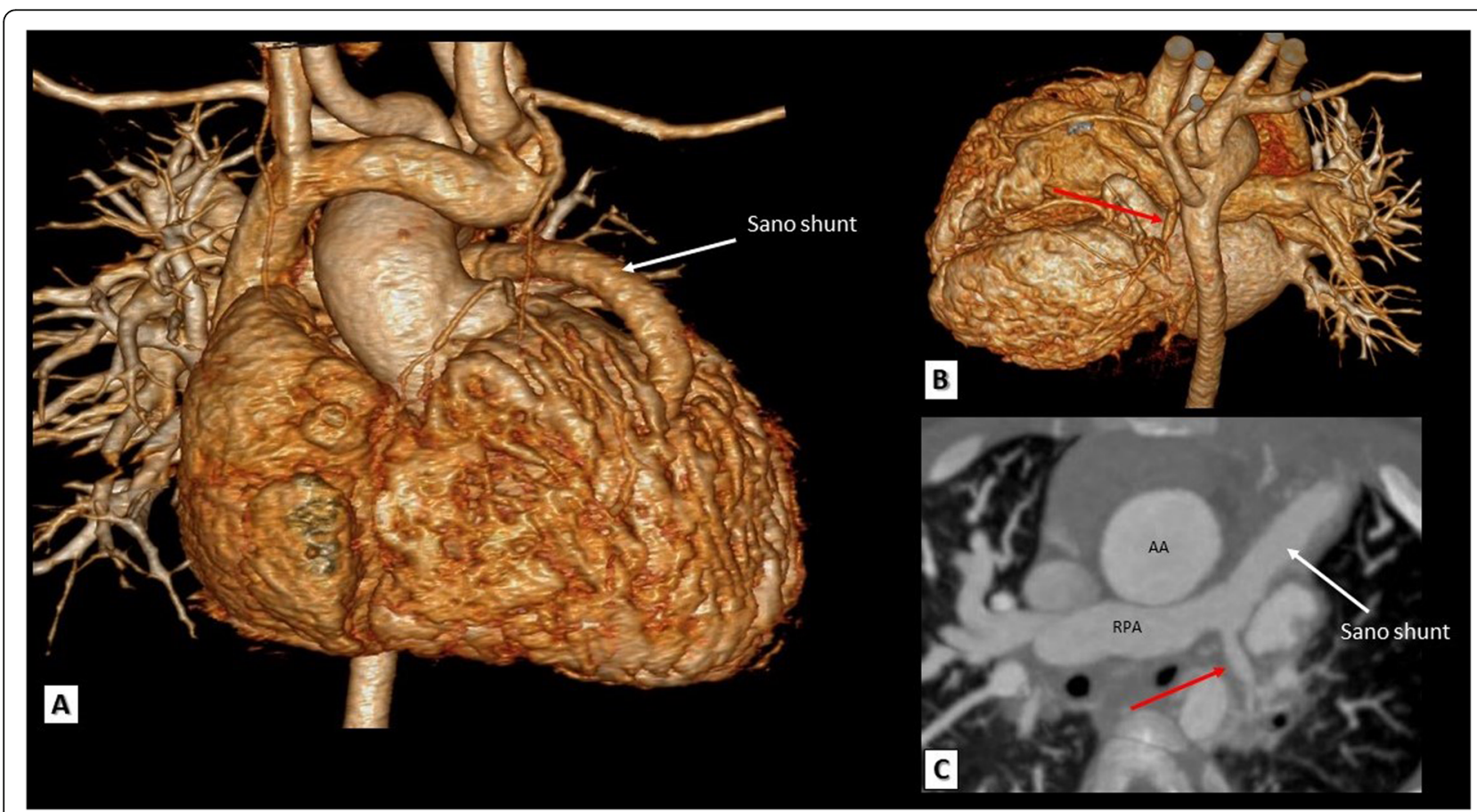

Fig. 11 A TOF patient with Sano shunt. a, b 3D VRT and $\mathbf{c}$ a reformatted axial MDCT image showing a patent Sano shunt between the RV and the distal main pulmonary artery. Note the hypoplastic left pulmonary artery (red arrows). AA, ascending aorta; RPA, right pulmonary artery 


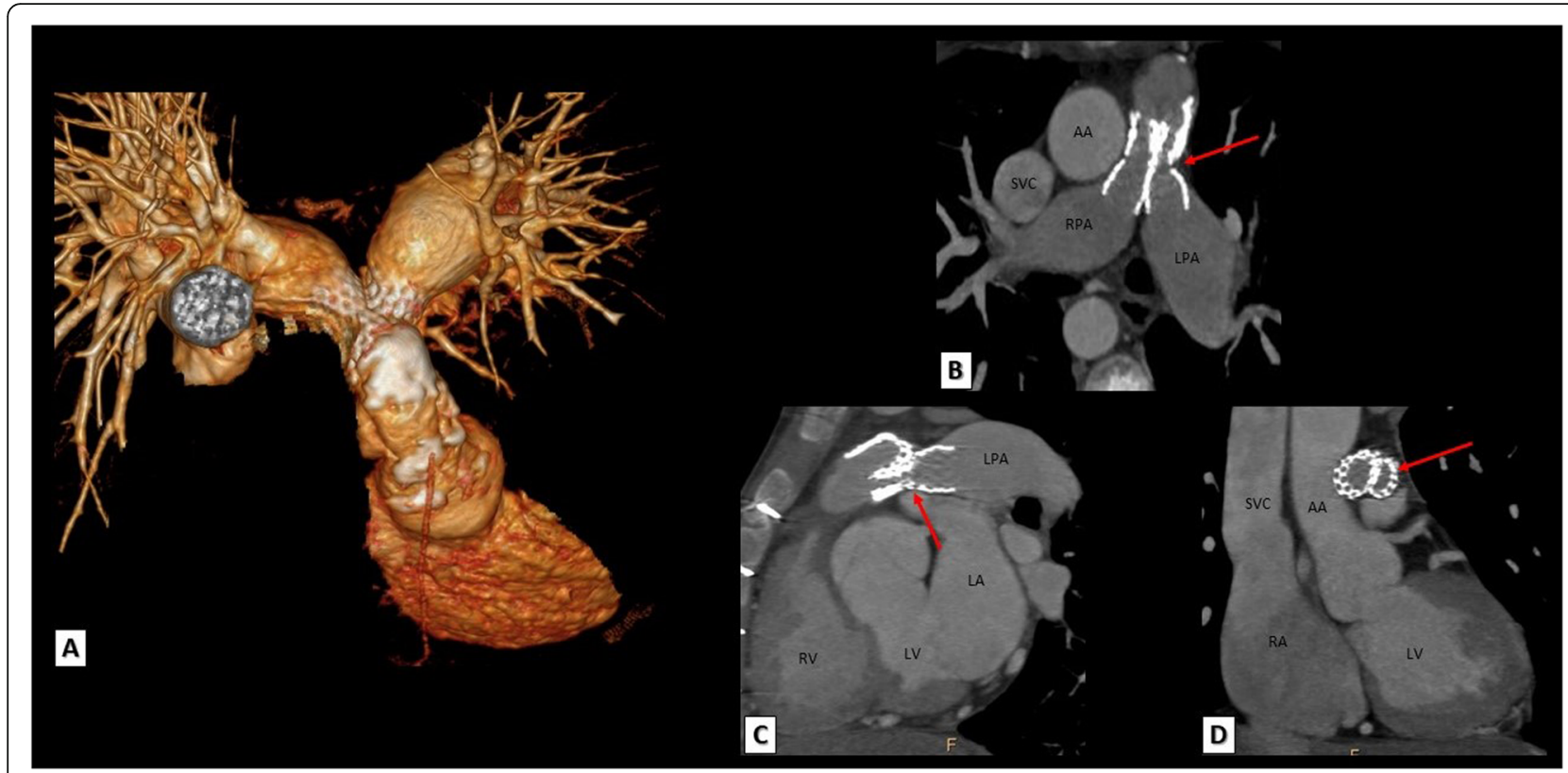

Fig. 12 A TOF patient with both right and left pulmonary arteries stenting. a 3D VRT, b reformatted axial, c reconstructed sagittal, and $\mathbf{d}$ reconstructed coronal images showing LPA stent fracture with significant narrowing of LPA ostium (red arrows). AA, ascending aorta; RPA, right pulmonary artery; LPA, left pulmonary artery; SVC, superior vena cava; LV, left ventricle; RV, right ventricle; LA, left atrium; RA, right atrium

\section{RVOT aneurysm}

RVOT aneurysm is defined as outward movement of part of the ventricular wall or its repaired outflow tract during systole which is reported to be an independent predictor of RV dilatation and systolic dysfunction in repaired TOF patients. It also provides a suitable substrate for ventricular arrhythmias. MDCT images clearly delineate RVOT aneurysms and any associated dilatation of main pulmonary artery and its central branches (Fig. 13).

\section{Conduit calcification and stenosis:}

Different types of conduits are used in the surgical repair of TOF. The immediate postoperative results are excellent but with time, progressive conduit obstruction occurs due to patient-prosthesis mismatch, distal anastomotic stenosis, conduit kinking, thrombosis, and calcifications. MDCT can accurately assess the exact mechanism of conduit obstruction, as well as assessment of stenosis level, degree, and extension (Fig. 14).

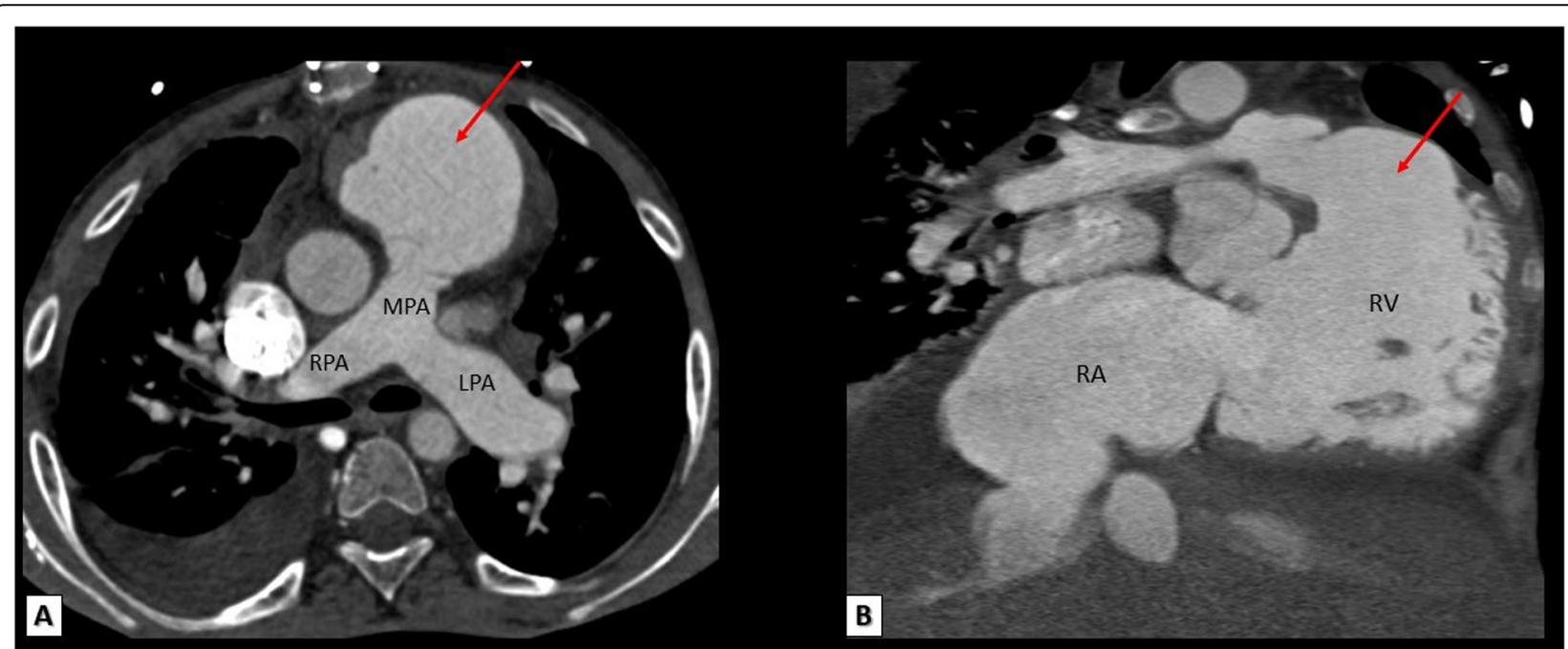

Fig. 13 A surgically repaired TOF patient. a Reformatted axial and $\mathbf{b}$ reformatted coronal MDCT images showing a large RVOT aneurysm (red arrows). MPA, main pulmonary artery; RPA, right pulmonary artery; LPA, left pulmonary artery; RV, right ventricle; RA, right atrium 


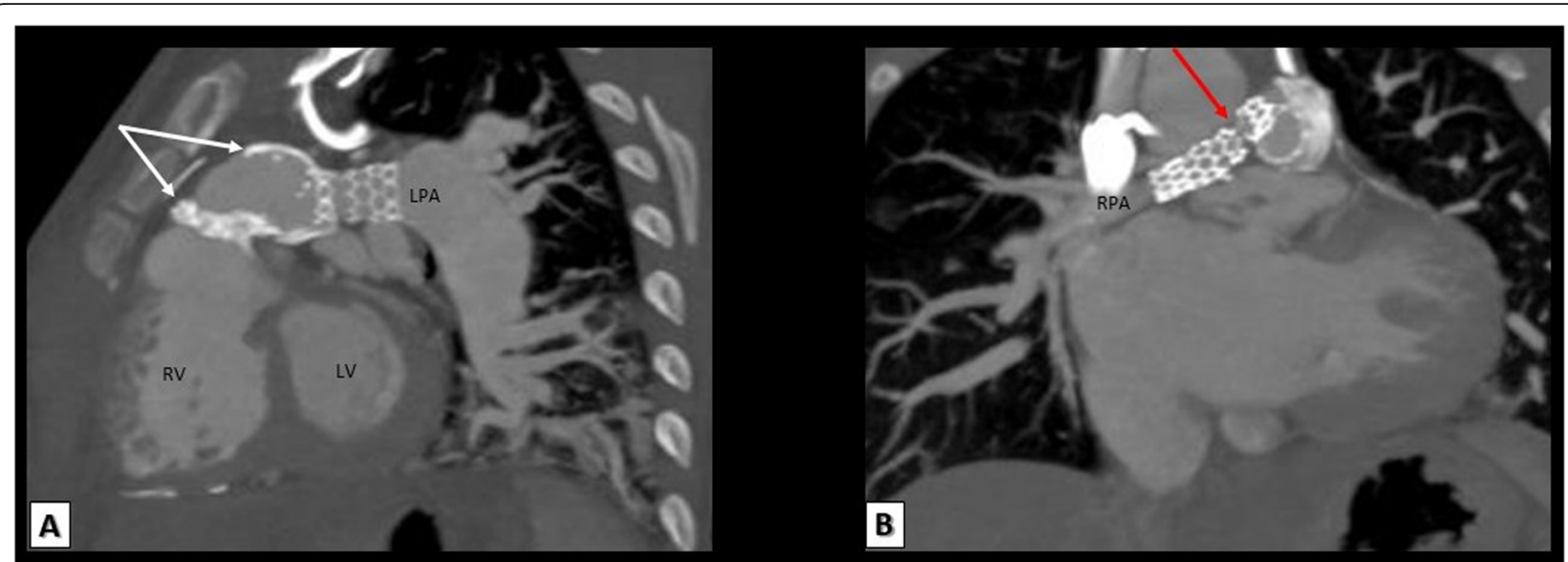

Fig. 14 Images of a surgically repaired TOF patient with RV-PA conduit and bilateral branch pulmonary artery stenting. a Reconstructed sagittal and $\mathbf{b}$ reconstructed coronal MDCT images showing marked calcifications of the RV-PA conduit. Note the fractured RPA stent (red arrow). RPA, right pulmonary artery; LPA, left pulmonary artery; LV, left ventricle; RV, right ventricle

\section{Conclusion}

Because of its wide availability and high spatial and temporal resolution, MDCT is being used with increasing frequency to evaluate patients with TOF. It can reliably and accurately assess complex anatomy and associated anomalies in unrepaired TOF patients and guide the surgical approach and type of surgery needed. In addition, MDCT has given us the opportunity to fully understand and assess the late surgical sequalae, complications, and residual lesions. Therefore, it is now essential that corrected TOF patients should have regular follow-up to assess residual lesions and the development of these complications to manage them correctly.

\section{Abbreviation \\ 3D: Three-dimensional; 4D: Four dimensional; ASD: Atrial septal defect; AVSD: Atrio-ventricular septal defect; CHD: Congenital heart disease; CMR: Cardiac magnetic resonance; DORV: Double orifice right ventricle; LAD: Left anterior descending; LM: Left main; LV: Left ventricle; MAPCA: Major aorto-pulmonary collateral artery; MBT: Modified Blalock-Taussig; MDCT: Multi-detector computed tomography; PDA: Patent ductus arteriosus; PFO: Patent foramen ovale; PG: Prostaglandin; PR: Pulmonary regurgitation; PV: Pulmonary valve; RCA: Right coronary artery; RV: Right ventricle; RVH: Right ventricular hypertrophy; RVOT: Right ventricle outflow tract; RVOTO: Right ventricle outflow tract obstruction; TOF: Tetralogy of Fallot; VSD: Ventricular septal defect}

\section{Acknowledgements}

Not applicable.

\section{Consent of publication}

Not applicable.

\section{Authors' contribution}

All authors read and accepted the final manuscript.

\section{Funding}

There was no source of funding for this study.

\section{Availability of data and materials}

The datasets used during the current study are available from the corresponding author on reasonable request.

\section{Competing interests}

The authors declare that they have no competing interests.

\section{Author details}

${ }^{1}$ Aswan Heart Centre (Magdi Yacoub Foundation), Aswan, Egypt. ${ }^{2}$ Cardiology department, Faculty of medicine, Tanta University, Tanta, Egypt. ${ }^{3}$ Radiology department, Faculty of medicine, Ain Shams University, Cairo, Egypt. ${ }^{4}$ Radiology department, Faculty of medicine, Alexandria University, Alexandria, Egypt. ${ }^{5}$ Radiology department, Faculty of medicine, Cairo University, Giza, Egypt.

Received: 14 November 2019 Accepted: 28 February 2020 Published online: 03 April 2020

\section{References}

1. Bertranou E, Blackstone E, Hazelrig J, Turner M, Kirklin JW (1978) Life expectancy without surgery in ToF. Am J Cardiol. 42:458

2. Fallot E. Contribution a lanatomie pathologique de la maladie bleue (cyanotic cardiaque). Marseille méd. 1888;25:77-138.

3. Sprengers RW, Roest AAW, Kroft LJM. Tetralogy of Fallot. 2017, 1-28.

4. Duro RP, Moura C, Leite-Moreira A (2010) Anatomophysiologic basis of tetralogy of Fallot and its clinical implications. Rev Port Cardiol 29(4):591630

5. Zubairi R, Malik S, Jaquiss RDB, Imamura M, Gossett J, Morrow WR (2011) Risk factors for prosthesis failure in pulmonary valve replacement. Ann Thorac Surg 91(2):561-565

6. Kanter KR, Budde JM, Parks WJ, Tam VK, Sharma S, Williams WH et al (2002) One hundred pulmonary valve replacements in children after relief of right ventricular outflow tract obstruction. Ann Thorac Surg 73(6):1801-1807

7. Fiore AC, Rodefeld M, Turrentine M, Vijay P, Reynolds T, Standeven J et al (2008) Pulmonary valve replacement: a comparison of three biological valves. Ann Thorac Surg 85(5):1712-1718

8. Karamlou T, Ungerleider RM, Alsoufi B, Burch G, Silberbach M, Reller M et al (2005) Oversizing pulmonary homograft conduits does not significantly decrease allograft failure in children. Eur J Cardio Thoracic Surg 27(4):548-553

9. Dadlani GH, John JB, Cohen MS (2008) Echocardiography in tetralogy of Fallot. Cardiol Young 18(S3):22-28

10. Need LR, Powell AJ, del Nido P, Geva T (2000) Coronary echocardiography in tetralogy of Fallot: diagnostic accuracy, resource utilization and surgical implications over 13 years. J Am Coll Cardiol 36(4):1371 LP-1371377

11. Lee W, Smith RS, Comstock CH, Kirk JS, Riggs T, Weinhouse E (1995) Tetralogy of Fallot: prenatal diagnosis and postnatal survival. Obstet Gynecol 86(4, Part 1):583-588

12. Kjaergaard J, Hassager C, Petersen CL, Kjaer A, Schaadt BK, Oh JK (2006) Evaluation of right ventricular volume and function by $2 \mathrm{D}$ and $3 \mathrm{D}$ echocardiography compared to MRI. Eur J Echocardiogr 7(6):430-438 
13. Roest AAW, Helbing WA, Kunz P, Van Den Aardweg JG, Lamb HJ, Vliegen HW et al (2002) Exercise MR imaging in the assessment of pulmonary regurgitation and biventricular function in patients after tetralogy of fallot repair. Radiology 223(1):204-211

14. Van den Berg J, Wielopolski PA, Meijboom FJ, Witsenburg M, Bogers AJ, Pattynama PM et al (2007) Diastolic function in repaired tetralogy of Fallot at rest and during stress: assessment with MR imaging. Radiology 243(1): 212-219

15. Therrien J, Provost Y, Merchant N, Williams W, Colman J, Webb G (2005) Optimal timing for pulmonary valve replacement in adults after tetralogy of Fallot repair. Am J Cardiol 95(6):779-782

16. Elliott RB, Starling MB, Neutze JM (1975) Medical manipulation Of The ductus arteriosus. Lancet 305(7899):140-142

17. Cumming G, Carr W (1966) Relief Of dyspnœic attacks In Fallot's tetralogy with propranalol. Lancet 287(7436):519-522

18. Garson A, Gillette PC, McNamara DG (1981) Propranolol: the preferred palliation for tetralogy of fallot. Am J Cardiol 47(5):1098-1104

19. Graham EM, Bandisode VM, Bradley SM, Crawford FA, Simsic JM, Atz AM (2008) Effect of preoperative use of propranolol on postoperative outcome in patients with tetralogy of fallot. Am J Cardiol 101(5):693-695

20. Tanaka K, Kitahata H, Kawahito S, Nozaki J, Tomiyama Y, Oshita S (2003) Phenylephrine increases pulmonary blood flow in children with tetralogy of Fallot. Can J Anesth 50(9):926-929

21. Bertranou EG, Blackstone EH, Hazelrig JB, Turner ME Jr, Kirklin JW (1978) Life expectancy without surgery in tetralogy of Fallot. Am J Cardiol 42(3):458466

22. Van Arsdell GS, Maharaj GS, Tom J, Rao VK, Coles JG, Freedom RM et al (2000) What is the optimal age for repair of tetralogy of Fallot? Circulation 102(suppl_3):|I1123-III129

23. Al Habib HF, Jacobs JP, Mavroudis C, Tchervenkov Cl, O'brien SM, Mohammadi S et al (2010) Contemporary patterns of management of tetralogy of Fallot: data from the Society of Thoracic Surgeons Database. Ann Thorac Surg 90(3):813-820

24. Karl TR, Sano S, Pornviliwan S, Mee RBB (1992) Tetralogy of Fallot: favorable outcome of nonneonatal transatrial, transpulmonary repair. Ann Thorac Surg 54(5):903-907

25. Jahangiri M, Lincoln C, Shinebourne EA (1999) Does the modified BlalockTaussig shunt cause growth of the contralateral pulmonary artery? Ann Thorac Surg 67(5):1397-1399

26. Dickinson DF, Wilkinson JL, Smith A, Hamilton DI, Anderson RH (1982) Variations in the morphology of the ventricular septal defect and disposition of the atrioventricular conduction tissues in tetralogy of Fallot. Thorac Cardiovasc Surg 30(05):243-249

27. Ricci M, Tchervenkov Cl, Jacobs JP, Anderson RH, Cohen G, Bove EL (2008) Surgical correction for patients with tetralogy of Fallot and common atrioventricular junction. Cardiol Young 18(S3):29-38

28. Chessa M, Giamberti A. The right ventricle in adults with tetralogy of Fallot. Italia: Springer; 2012. https://doi.org/10.1007/978-88-470-2358-1.

29. Bharati S, Kirklin JW, McAllister HA Jr, Lev M (1980) The surgical anatomy of common atrioventricular orifice associated with tetralogy of Fallot, double outlet right ventricle and complete regular transposition. Circulation 61(6): 1142-1149

30. Li J, Soukias ND, Carvalho JS, Ho SY (1998) Coronary arterial anatomy in tetralogy of Fallot: morphological and clinical correlations. Heart 80(2):174183

31. Chessa M, Giamberti A, Foresti S, Ranucci M (2014) Tetralogy of fallot in the adult. Pediatr Congenit Cardiol Card Surg Intensive Care:2551-2568

\section{Publisher's Note}

Springer Nature remains neutral with regard to jurisdictional claims in published maps and institutional affiliations.

\section{Submit your manuscript to a SpringerOpen ${ }^{\circ}$ journal and benefit from:}

- Convenient online submission

- Rigorous peer review

- Open access: articles freely available online

High visibility within the field

- Retaining the copyright to your article

Submit your next manuscript at $\boldsymbol{\nabla}$ springeropen.com 